\title{
Efeito da solução nutritiva sob o crescimento e composição mineral em pepino cultivado em substrato de fibra de coco
}

\section{Nutrient solution effect on development and mineral composition of cucumber grown in coconut fiber substrate}

\author{
Adriana Araujo Diniz ${ }^{1 *}$; Nildo da Silva Dias ${ }^{1}$; \\ Francisco Ismael de Souza²; Ana Cláudia Medeiros Souza ${ }^{3}$; \\ Francisco de Oliveira Mesquita ${ }^{3}$; Francisco Irael de Souza ${ }^{4}$
}

\begin{abstract}
Resumo
O pepino é uma importante hortaliça amplamente cultivada por pequenos e médios produtores no semiárido do Brasil. O experimento foi desenvolvido com o objetivo de avaliar os efeitos de diferentes soluções nutritivas do pepino cultivado em substrato de fibra de coco sob o crescimento e composição mineral de folhas. O delineamento experimental foi o de blocos casualizados com quatro repetições. A solução nutritiva padrão foi preparada seguindo a recomendação de $100 \%$ sugerida por Furlani para a cultura do pepino. A partir dessa recomendação, foram testadas novas concentrações de nutrientes: 12,5; $17 ; 25 ; 50$ e 100\%, que após a diluição dos nutrientes apresentou condutividades de 1,$0 ; 1,2 ; 1,5 ; 2,3$ e $3,8 \mathrm{dS} \mathrm{m}^{-1}$, respectivamente. A partir dos sete dias após o transplantio foram medidas as variáveis altura de plantas, diâmetro caulinar e número de folhas. No início da floração (30 dias após o transplantio) foram coletadas de cada parcela duas folhas por planta, a partir do broto terminal, para determinação dos teores de macro e micronutrientes na biomassa seca das folhas. As variáveis de crescimento altura de plantas, diâmetro do caule e número de folhas foram influenciadas pela interação proporção de nutrientes na solução nutritiva $\times$ idade das plantas. As plantas de pepineiro estavam adequadamente nutridas em nitrogênio $(\mathrm{N})$, fósforo $(\mathrm{P})$, potássio $(\mathrm{K})$, cálcio $(\mathrm{Ca})$, magnésio $(\mathrm{Mg})$, cobre $(\mathrm{Cu})$, manganês $(\mathrm{Mn})$, ferro $(\mathrm{Fe})$ e zinco $(\mathrm{Zn})$.

Palavras-chave: Cucumis sativus L., cultivo hidropônico, nutrição de plantas
\end{abstract}

\begin{abstract}
Cucumber is an important horticultural crop widely cultivated for small and medium growers in semiarid regions of the Brazil. In order to evaluate the nutrient solution effect on development and mineral composition of cucumber grown in coconut fiber substrate, an experimental was carried out using completely randomized design with four replications. A standard nutrient solution was prepared following the recommendation of $100 \%$ suggested by Furlani for cucumber crop. Concentrations of nutrient solution were to simulate by standard nutrient solution: $12.5,17,25 ; 50$ and $100 \%$ (control) and, after the nutrients dilution showed conductivities following: 1.0, 1.2, 1.5, 2.3 and $3.8 \mathrm{dS} \mathrm{m}^{-1}$, respectively. Seven days after transplanting the variables plant height, stem diameter and number of
\end{abstract}

${ }^{1}$ Eng $^{\text {os }}$ Agr $^{\text {os }}$, Drs., Dept ${ }^{\circ}$ de Ciências Ambientais e Tecnológicas, Universidade Federal Rural do Semi Árido, UFERSA, Mossoró, RN. E-mail: adriana@ufersa.edu.br; nildo@ufersa.edu.br

2 Eng $^{\circ}$ Agr $^{\circ}$, UFERSA, Mossoró, RN. E-mail: ismaelsouza38@hotmail.com

3 Discentes de Doutorado do Programa de Pós Graduação em Manejo de Solo e Água, UFERSA, Mossoró, RN. E-mail: anaclaudia. gambiental@hotmail.com; mesquitaagro@yahoo.com.br

4 Discente de Mestrado do Programa de Pó Graduação em Manejo de Solo e Água, UFERSA, Mossoró, RN. E-mail: franciscoirael@ hotmail.com

* Autor para correspondência 
leaves were recording. For each plot two leaves of cucumber terminal shoot was collected at beginning of flowering (30 days after transplanting) and, macro and micronutrients was analyzed in dry biomass. Growth variables plant height, stem diameter and number of leaves were influenced by the interaction ratio of nutrients in the nutrients solution age of the plants. The cucumber plants were adequately nourished in nitrogen, phosphorus, potassium, calcium, magnesium, copper, manganese, iron and zinc.

Key words: Cucumis sativus L., hydroponic, plant nutrition

\section{Introdução}

O pepino é uma das hortaliças mais cultivadas em ambiente protegido (CARDOSO; WILCKEN, 2008), em virtude do cultivo em ambiente protegido proporcionar maior controle de pragas e doenças sobre a cultura o que irá se refletir em maiores ganhos na produção final. Do ponto de vista técnico, o sistema de cultivo em ambiente protegido tem proporcionado a produção da cultura fora de época, reduzido custos e elevando a produtividade, principalmente quando aliado ao sistema hidropônico (FACTOR; ARAÚJO; VILELLA JÚNIOR, 2008).

O estado nutricional pode influir na produção da biomassa e na qualidade do produto (SKREBSKY, 2007), assim, é necessário manter a qualidade nutricional do pepino em todas as etapas do processo produtivo. Para Fernandes, Martinez e Oliveira (2002), a formulação de solução nutritiva para hortaliças de frutos é o processo mais complexo, tendo em vista que além da fase vegetativa acrescenta-se as fases de florescimento e frutificação.

Fernandes, Martinez e Oliveira (2002) relatam que são essenciais os estudos sobre nutrição mineral de hortaliças cultivadas em hidroponia para o estabelecimento das exigências nutricionais de cada espécie, tanto para as formulações das soluções nutritivas nos estádios vegetativo e reprodutivo, quanto para a reposição periódica dos nutrientes durante o desenvolvimento da cultura.

Nesse sentido, os nutrientes podem ser absorvidos em diferentes quantidades, de acordo com as condições em que a planta se encontra. Para se obter alta produtividade das plantas, os nutrientes devem ser fornecidos em quantidades e proporções adequadas em todas as fases do seu ciclo (PAPADOPOULOS, 1994). Portanto, o uso de uma solução nutritiva que atenda às exigências nutricionais da cultura é o primeiro passo para o sucesso do cultivo hidropônico. Devido a esses fatos e associado a escassez de informações recentes quanto a composição mineral das folhas, trabalhos relacionados com o estado nutricional de plantas merecem destaque pelo fato de que podem ser determinantes em todas as etapas do ciclo da cultura.

Diante da importância da cultura do pepino, e da necessidade de formular uma proporção de nutrientes que seja mais viável para o produtor, este trabalho foi realizado com objetivo de avaliar os efeitos da aplicação de concentrações de nutrientes na solução nutritiva do pepino cultivados em substrato de fibra de coco sob o crescimento e composição mineral das folhas.

\section{Material e Métodos}

A pesquisa foi realizada em ambiente protegido no Departamento de Ciências Ambientais e Tecnológicas da Universidade Federal Rural do Semi-Árido (UFERSA), em de Mossoró, RN (5¹1' de LS e $37^{\circ} 20^{\prime}$ de $\mathrm{LO}$ e com altitude de $18 \mathrm{~m}$ ). O clima local é do tipo BSwh' com base na classificação de Köppen e a média anual de precipitação é da ordem de com média de $672,9 \mathrm{~mm}$, e umidade relativa de 68,9\% (CARMO FILHO; OLIVEIRA, 1995).

O ambiente protegido utilizado foi do tipo capela, com pé direito de 3,0 m, 12,0 m de comprimento e $16,0 \mathrm{~m}$ de largura, coberto com filme de polietileno de baixa densidade, com aditivo anti UV e espessura de 150 micras, protegido nas laterais com tela preta. 
O sistema de irrigação adotado foi o localizado, utilizando-se emissores do tipo microtubos de 1,5 mm de diâmetro interno. A solução nutritiva foi fornecida através de reservatórios individuais, com capacidade de $300 \mathrm{~L}$ cada, suspensos de forma a obter-se uma coluna de água de 1,2 m.

As mudas de pepino da variedade Magnum caipira híbrido F1foram produzidas em bandejas de 180 células, sendo colocada uma semente de pepino por célula e durante uma semana foram irrigadas duas vezes por dia, utilizando-se um regador com água de abastecimento $\left(\mathrm{CE}=0,5 \mathrm{dS} \mathrm{m}^{-1}\right)$. Quando as plântulas estavam com 13 dias foram transplantadas para vasos plásticos com volume de 8 litros contendo o substrato de fibra de coco.

As plantas foram tutoradas verticalmente com auxílio de barbante e os demais tratos culturais foram realizados mediante recomendação de Filgueira (2008). Foram plantadas 20 mudas de pepino como bordadura, lateralmente a área experimental. Cada parcela experimental foi composta por um sistema hidropônico, constituído por 5 vasos de plástico de $8 \mathrm{~L}$, espaçados em $0,5 \mathrm{~m}$ entre vasos e $1,0 \mathrm{~m}$ entre linhas, sendo furados na base para a drenagem da água em excesso. Os vasos foram preenchidos com fibra de coco e colocados sobre um suporte a 0,1 $\mathrm{m}$ do nível do solo do ambiente protegido, com a finalidade de evitar o contato direto do vaso com o piso da estufa, e para facilitar o processo de drenagem.

O delineamento experimental adotado foi o de blocos casualizados, com quatro repetições, e 5 plantas por parcela, sendo avaliados os efeitos de cinco concentrações de solução nutritiva. A solução nutritiva foi preparada seguindo a recomendação de 100\% sugerida por Furlani et al. (1999) para a cultura do pepino. A partir dessa recomendação, foram testadas novas concentrações de nutrientes proporcionais $\left(\mathrm{T}_{1}=12,5 ; \mathrm{T}_{2}=17 ; \mathrm{T}_{3}=25 ; \mathrm{T}_{4}=50\right.$ e $\mathrm{T}_{5}=100 \%$ ). Utilizou-se 300 litros de água, com as seguintes quantidades de macronutrientes nos tratamentos $\mathrm{T}_{1}$ : $(20,7 ; 9,3 ; 11,6 ; 44,7$ e $22,2 \mathrm{~g}) ; \mathrm{T}_{2}$ :
$(27,6 ; 12,4 ; 15,4 ; 59,7$ e 29,6 g); T3: $(41,3 ; 18,5$; $23,1 ; 89,5$ e $44,4 \mathrm{~g})$; T4: $(82,7 ; 37,0 ; 46,5 ; 179,0$ e 88,9 g) e T5: $(165,3 ; 74,1 ; 92,5 ; 357,8$ e 177,8 g) de N-KNO3; P-MAP; K-KCl; Ca-CaNO3 e Mg$\mathrm{MgSO} 4$, respectivamente, para cada tratamento.

Para o preparo dos micronutrientes (M) também seguiu-se a recomendação de Furlani et al. (1999) e foram adicionados 5,9 $\mathrm{g}$ de $\mathrm{B}-\mathrm{H} 3 \mathrm{BO} 3 ; 0,8 \mathrm{~g}$ de $\mathrm{Cu}-$ CuSO4; 3,1 g de Mn-MnSO4; 0,3 g de Mo-Na2. $\mathrm{MOO} 4.2 \mathrm{H} 2 \mathrm{O}$ e 3,0 g de $\mathrm{Zn}-\mathrm{ZnSO} 4$ em um litro de água deionizada. E como fonte de $\mathrm{Fe}(\mathrm{F})$ adicionouse 33,9 $\mathrm{g}$ de Fe em um litro de água deionizada. No preparo das soluções nutritivas foram adicionados no tratamento T1: $25 \mathrm{~mL}$ de $\mathrm{M}$ e $25 \mathrm{~mL}$ de F; T2: 33 $\mathrm{mL}$ de $\mathrm{M}$ e $33 \mathrm{~mL}$ de F; T3: $50 \mathrm{~mL}$ de $\mathrm{M}$ e $50 \mathrm{~mL}$ de F; T4: $100 \mathrm{~mL}$ de M e $100 \mathrm{~mL}$ de F e T5: $200 \mathrm{~mL}$ de M e $200 \mathrm{~mL}$ de F, que após a diluição dos nutrientes, a solução nutritiva apresentou $\mathrm{CE}$ da solução de $\mathrm{T} 1=1,0 ; \mathrm{T} 2=1,2 ; \mathrm{T} 3=1,5 ; \mathrm{T} 4=2,3$ e T5=3,8 dS m-1, respectivamente.

Para preparar a solução nutritiva utilizou-se água do sistema de abastecimento público do campus da UFERSA. As características químicas das águas utilizadas nos experimentos encontram-se na Tabela 1. Pelos dados, é possível verificar a baixa CE da água utilizada no preparo da solução nutritiva.

A partir dos sete aos 42 dias após o transplantio foram efetuadas leituras em altura das plantas $(\mathrm{cm})$, diâmetro do colo com um paquímetro $(\mathrm{mm})$ e foi contado o número de folhas das plantas de pepineiro. No início da floração, quando as plantas estavam com aproximadamente 30 dias após o transplantio foram coletadas de cada parcela duas folhas planta ${ }^{-1}$ (quarta e quinta folha), totalizando dez folhas por parcela, a partir do broto terminal das plantas, para determinação dos teores de macro e micronutrientes na biomassa seca das plantas Malavolta, Vitti e Oliveira (1997).

Os dados foram submetidos à análise de variância (ANOVA) e teste $\mathrm{F}$ usando o programa SISVAR (FERREIRA, 2000). 
Tabela 1. Caracterização química da água utilizada no preparo das soluções nutritivas.

\begin{tabular}{cccccccccc}
\hline \multirow{2}{*}{ Fonte } & \multirow{2}{*}{$\mathrm{CE}\left(\mathrm{dS} \mathrm{m}{ }^{-1}\right)$} & \multirow{2}{*}{$\mathrm{pH}$} & $\mathrm{Ca}^{2+}$ & $\mathrm{Mg}^{2+}$ & $\mathrm{Na}^{+}$ & $\mathrm{Cl}^{-}$ & $\mathrm{CO}_{3}^{2-}$ & $\mathrm{HCO}_{3}^{-}$ & $\mathrm{RAS}$ \\
\cline { 4 - 9 } & & & & $\ldots \ldots \ldots \ldots \ldots \ldots \mathrm{mmol}_{c} \mathrm{~L}^{-1} \ldots \ldots \ldots \ldots \ldots \ldots \ldots \ldots$ & $\ldots \ldots \ldots \ldots \ldots \ldots \ldots$ & \\
\hline $\mathrm{AU}$ & 0,46 & 8,0 & 0,6 & 0,1 & 5,1 & 1,8 & 0,5 & 3,8 & 8,62 \\
\hline
\end{tabular}

$\mathrm{AU}=$ Abastecimento da Ufersa; $\mathrm{CE}$ : Condutividade Elétrica; $\mathrm{pH}$ : potencial de Hidrogênio; $\mathrm{Ca}^{2+}$ : Cálcio; $\mathrm{Mg}^{2+}: \mathrm{Magnésio} ; \mathrm{Na}^{+}$: Sódio; $\mathrm{Cl}:$ : Cloro; $\mathrm{CO}_{3}^{2}$-: Carbonato; $\mathrm{HCO}_{3}^{-}$: Bicarbonato; RAS: Reação de Adsorção de Sódio.

Fonte: Elaboração dos autores.

\section{Resultados e Discussão}

De acordo com a análise de variância, observouse que as variáveis altura de plantas, diâmetro caulinar e número de folhas do pepineiro foram influenciados significativamente pela idade das plantas e proporção de nutrientes na solução nutritiva, havendo interação idade das plantas $\times$ proporções de nutrientes na solução nutritiva (Tabela 2).

Tabela 2. Análises de variância (ANOVA) para as variáveis altura de plantas (AP), diâmetro caulinar (DC) e número de folhas (NF) do pepineiro em função da idade e da aplicação de proporções de nutrientes na solução nutritiva.

\begin{tabular}{|c|c|c|c|c|}
\hline \multirow{2}{*}{ FV } & \multirow[b]{2}{*}{ GL } & \multicolumn{3}{|c|}{ Quadrados Médios } \\
\hline & & AP & $\mathrm{DC}$ & NF \\
\hline Idade (I) & 4 & $48248,77^{* * *}$ & $83,82 * *$ & $3654,31 * *$ \\
\hline SN & 4 & $4719,92 * *$ & $16,67 * *$ & $112,92 * *$ \\
\hline I X SN & 16 & $1112,35^{* *}$ & $0,99 * *$ & $52,95 * *$ \\
\hline Bloco & 3 & 90,93 & 0,67 & 4,21 \\
\hline Erro & 72 & 70,16 & 0,64 & 3,94 \\
\hline $\mathrm{CV}(\%$ & & 8,62 & 6,88 & 8,22 \\
\hline
\end{tabular}

$\mathrm{FV}=$ fonte de variação; $\mathrm{SN}=$ solução nutritiva; $\mathrm{GL}$ = graus de liberdade; $\mathrm{ns}=$ não significativo; * $\mathrm{e} * *$ respectivamente significativos para $\mathrm{p} \leq 0,05$ e $\mathrm{p} \leq 0,01 ; \mathrm{CV}=$ Coeficiente de variação.

Fonte: Elaboração dos autores.

As variáveis altura (Figura 1A), diâmetro caulinar (Figura 1B) e o número de folhas (Figura 1C) aumentaram com a idade das plantas. Conforme indicado na Figura 1A, dos 14 aos 42 dias após o transplantio (DAP), as plantas tiveram um incremento em altura de 22,8 para $187,2 \mathrm{~cm}$ em função das proporções de nutrientes aplicadas ao substrato de fibra de coco. Comparativamente, verificou-se que dos 14 aos 42 DAP as plantas cresceram no $\mathrm{T}_{1}(12,5 \%)$ de 22,8 para até $164,1 \mathrm{~cm}$, no $\mathrm{T}_{2}(17 \%)$ de 26,6 a $134,8 \mathrm{~cm}$; no $\mathrm{T}_{3}(25 \%)$ de
26,0 para $155,3 \mathrm{~cm}$; no $\mathrm{T}_{4}(50 \%)$ de 26,1 para 98,7 $\mathrm{cm}$ e no $\mathrm{T}_{5}(100 \%)$ de 26,6 para $187,2 \mathrm{~cm}$. O maior crescimento em altura foi obtido no $\mathrm{T}_{1}(12,5 \%)$, tratamento esse que continha o menor percentual de nutrientes, inclusive $\mathrm{N}$, que é responsável pelo crescimento e perfilhamento das plantas (MALAVOLTA; VITTI; OLIVEIRA, 1997). As plantas tiveram seu crescimento em altura médio aumentado em até $10,37 \%$, haja vista, que esse incremento corresponde à maior e menor proporção de nutriente na solução. 
Figura 1. Altura (A), diâmetro (B) e número de folhas (C) de plantas de pepino em função de proporções de nutrientes na solução nutritiva e da idade das plantas após o transplantio.

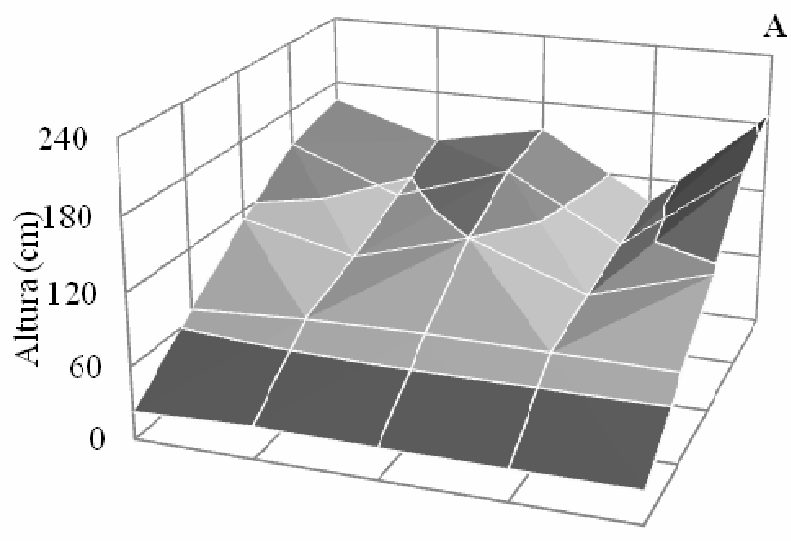

A
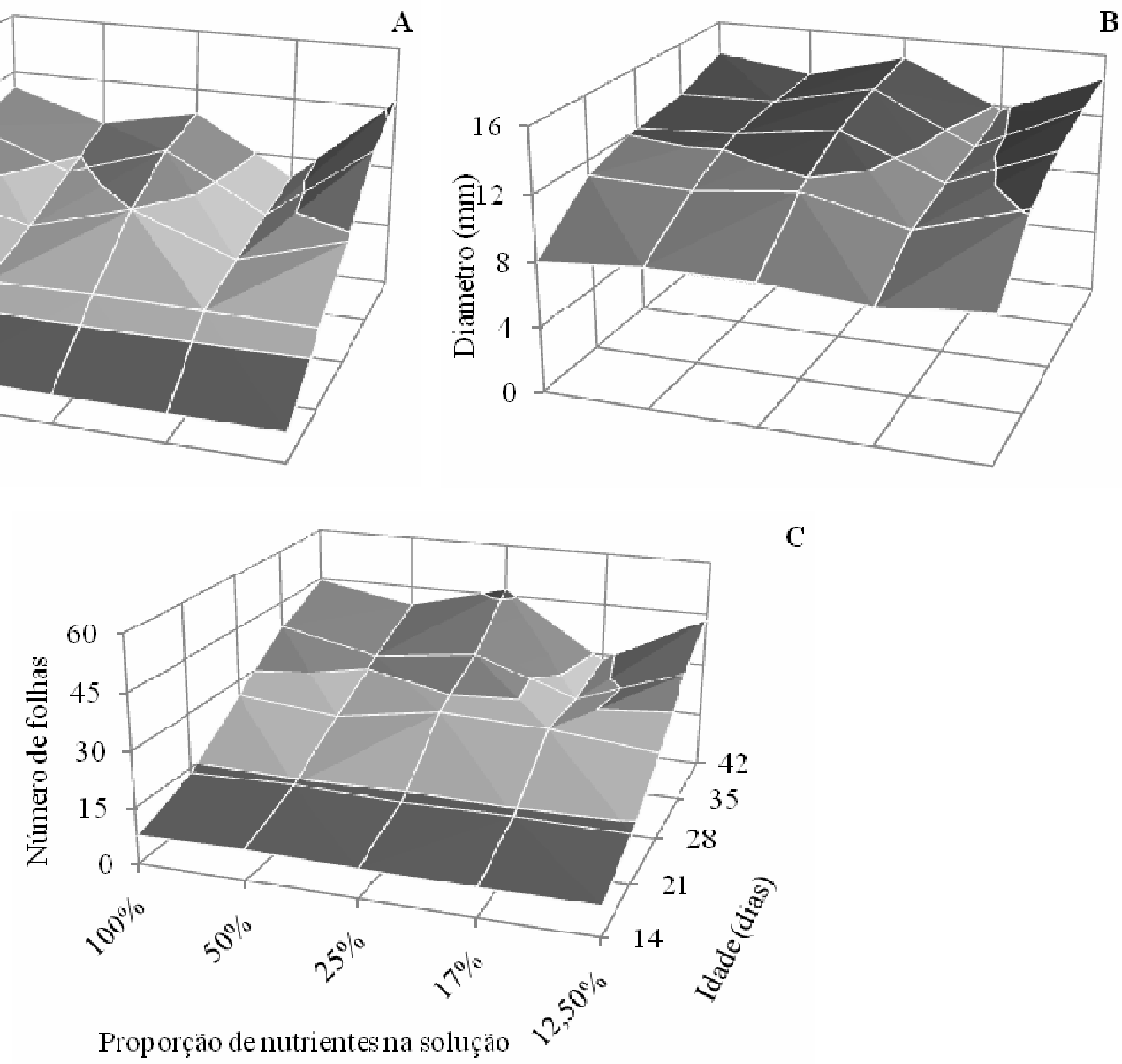

$\mathrm{C}$

Fonte: Elaboração dos autores.

As proporções de nutrientes aplicadas ao substrato propiciaram um aumento no diâmetro caulinar das plantas de pepino (Figura 1B) com a idade das plantas. Dos 14 aos 42 dias após o plantio, o diâmetro das plantas aumentou de 8,0 para 14,7 $\mathrm{mm}$. Sendo que no $\mathrm{T}_{1}$ a variação foi de 8,0 à 13,7 $\mathrm{mm}$, no $\mathrm{T}_{2}$ de 8,6 à 13,0 mm, no $\mathrm{T}_{3}$ de 8,6 à $14,7 \mathrm{~mm}$, no $\mathrm{T}_{4}$ de 8,13 à $11,8 \mathrm{~mm}$ e no $\mathrm{T}_{5}$ a variação foi de 8,7 à $14,4 \mathrm{~mm}$. Apesar da pouca variação do diâmetro das plantas ao longo de 42 dias, a proporção 12,5\% apresentou superioridade no seu diâmetro caulinar em até $8,81 \%$, esses valores se referem a maior (100\%) e menor (12,5\%) proporção de nutriente da solução nutritiva. Tendências de resultados semelhantes foram registrados por Dias et al. (2006) ao avaliarem a salinidade e manejo da fertirrigação em ambiente protegido sobre o rendimento do meloeiro, verificarem que, o diâmetro do colo foi afetado linearmente pela salinidade inicial do solo, em todas as medições efetuadas, exceto aos 34 dias após o transplantio.

Dias et al. (2010) também verificaram que o diâmetro do colo de plantas de melão cultivado em substrato de fibra de coco diferiu significativamente entre os níveis de salinidade da solução nutritiva apenas nas leituras aos 35 e 50 DAT, com efeito da condutividade elétrica da solução nutritiva sobre o diâmetro de plantas de melão rendilhado.

Quanto ao número de folhas (Figura 1C), no 
período de 14 a 42 dias após o transplantio, em função das proporções de nutrientes na solução nutritiva no $\mathrm{T}_{1}(12,5 \%)$, foi observado que o número de folhas aumentou na amplitude de 8 a 45 folhas por planta, no $\mathrm{T}_{2}(17 \%)$ a variação foi de 8,0 à 40 folhas por planta, no $\mathrm{T}_{3}$ foi de 8 à 47 folhas por planta, no $\mathrm{T}_{4}$ foi de 8 à 28 folhas por planta e no $\mathrm{T}_{5}$ foi de 8 a 43 folhas por planta. Apesar da pouca expressividade estatística, ainda assim, a proporção $25 \%\left(\mathrm{~T}_{3}\right)$ de nutrientes foi a que expressou melhores resultados.

Assim como observado para a altura de plantas, o incremento das concentrações de nutrientes resultou em aumento do número de folhas, mesmo com o aumento da salinidade da solução de 1,0 para até 3,8 dS m $\mathrm{dem}^{-1}$ em função do incremento dos nutrientes na solução. A tolerância do pepino à salinidade da solução nutritiva sobre as variáveis de crescimento (altura, diâmetro e número de folhas) pode ser atribuída ao sistema de cultivo em fibra de coco, visto que a alta capacidade de absorção hídrica deste substrato, cerca de $85 \%$ de umidade, dilui a concentração dos nutrientes no meio de crescimento e, consequentemente, os efeitos deletérios da salinidade sobre o crescimento das plantas. Além disso, o uso do substrato torna o potencial matricial inerte não interferindo na força de retenção de água e, em contrapartida, reduziu a dificuldade de absorção de água pelas plantas do meio (DIAS et al., 2010).

A aplicação de proporções de nutrientes na solução nutritiva exerceu efeitos significativos sobre os teores foliares de $\mathrm{N}, \mathrm{P}, \mathrm{K}, \mathrm{Ca}$ e $\mathrm{Mg}$ nas folhas das plantas de pepino (Tabela 3). A adição de diferentes proporções de nutrientes na solução nutritiva influenciou estatisticamente os teores de $\mathrm{N}, \mathrm{P}, \mathrm{K}$ e Ca na matéria seca foliar das plantas de pepino. Os teores foliares de $\mathrm{N}$ nas plantas, em função do incremento nos níveis de nutrientes da solução, foram elevados para teores de até $53,5 \mathrm{~g}$ $\mathrm{kg}^{-1}$ referente a dose ótima estimada de $57,3 \%$ da solução nutritiva recomendada (Figura 2A). Estes valores foram superiores aos obtidos por Fernandes, Martinez e Oliveira (2002), que encontraram concentrações médias de $43 \mathrm{~g} \mathrm{~kg}^{-1}$ de $\mathrm{N}$ e superiores a variação de 25 a $45 \mathrm{~g} \mathrm{~kg}^{-1}$ indicados por Vetanovetz (1996). Além disso, estão inseridos na faixa tida como ideal para a cultura, que varia na amplitude de 30 a $60 \mathrm{~g} \mathrm{~kg}^{-1}$ mencionados por Papadopoulos (1994).

Tabela 3. Análises de variância, referentes aos valores de quadrado médio para os teores foliares de nitrogênio $(\mathrm{N})$, fósforo $(\mathrm{P})$, potássio $(\mathrm{K})$, cálcio $(\mathrm{Ca})$ e magnésio $(\mathrm{Mg})$ do pepineiro, em função da aplicação de proporções de nutrientes na solução nutritiva.

\begin{tabular}{ccccccc}
\hline \multirow{2}{*}{ FV } & & \multicolumn{5}{c}{ Quadrados Médios } \\
\cline { 3 - 7 } & GL & $\mathrm{N}$ & $\mathrm{P}$ & $\mathrm{K}$ & $\mathrm{Ca}$ & $\mathrm{Mg}$ \\
\hline Bloco & 3 & $3207,733^{\text {ns }}$ & $5576,066^{\text {ns }}$ & $74080,733^{\text {ns }}$ & $36854,133^{\text {ns }}$ & $360,316^{\text {ns }}$ \\
SN & 4 & $2458228,950^{* *}$ & $61863,825^{* *}$ & $614541,800^{* *}$ & $414138,800^{* *}$ & $24791,825^{*}$ \\
Resíduo & 12 & 59515,983 & 12724,358 & 137978,233 & 15472,133 & 8239,858 \\
\hline CV $(\%)$ & 19 & 5,43 & 11,78 & 7,49 & 4,21 & 13,52 \\
\hline
\end{tabular}

$\mathrm{FV}=$ fonte de variação; $\mathrm{SN}=$ solução nutritiva; $\mathrm{GL}=$ graus de liberdade; ns = não significativo; * $\mathrm{e} * *$ respectivamente significativos para $\mathrm{p} \leq 0,05$ e $\mathrm{p} \leq 0,01 ; \mathrm{CV}=$ Coeficiente de variação.

Fonte: Elaboração dos autores. 
Silva et al. (2011) ao avaliarem os efeitos da não verificaram efeitos dos tratamentos sobre as omissão parcial de $\mathrm{N}, \mathrm{Mg}, \mathrm{S}$ e Fe em plantas de variáveis altura de plantas, número de folhas e pepino crescidas em solo com solução nutritiva,

diâmetro do caule até os 14 dias após o transplantio.

Figura 2. Teores foliares de nitrogênio (A), fósforo (B), potássio (C), cálcio (D) e magnésio (E) em plantas de pepino, em função de proporções de nutrientes na solução nutritiva.
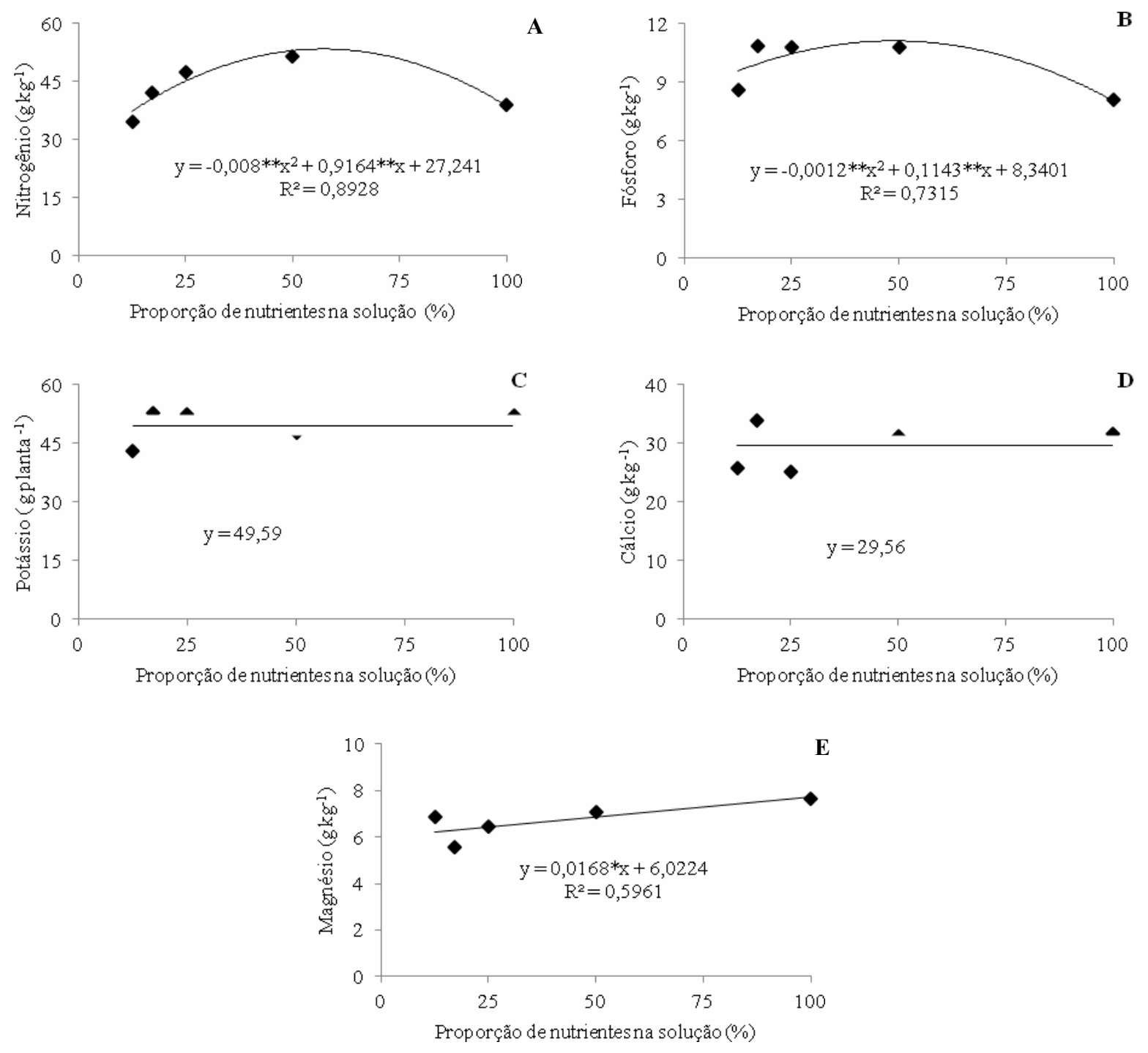

Fonte: Elaboração dos autores.

Os valores de fósforo ajustaram-se ao modelo quadrático de regressão, tendo seus valores aumentados até um maior valor de $11,1 \mathrm{~g} \mathrm{~kg}^{-1}$ correspondente a dose de solução nutritiva estimada de 47,6\% (Figura 2B), a partir dessa dose houve decréscimo nos teores. Esse valor foi superior ao valor médio de $8 \mathrm{~g} \mathrm{~kg}^{-1}$ obtido por Fernandes,
Martinez e Oliveira (2002) em plantas de pepino cultivadas em hidroponia e estão dentro da faixa indicada por Papadopoulos (1994) como ideal para plantas de pepino que é de 3 a $13 \mathrm{~g} \mathrm{~kg}^{-1}$ e foram superiores a variação de 4 a $8 \mathrm{~g} \mathrm{~kg}^{-1}$ indicados por Vetanovetz (1996). 
De acordo com Blanco (2006) a absorção de P aumenta rapidamente com o início da produção, sendo que aproximadamente $80 \%$ do P é absorvido entre 48 e 72 dias após a emergência, período em que se concentra a maior parte da produção de frutos, uma vez que os frutos acumulam em torno de 50\% do $\mathrm{P}$ absorvido, nesse aspecto os teores do referido experimento poderiam ainda ser maiores, já que o material coletado para análise foliar foi no início da floração (MALAVOLTA; VITTI; OLIVEIRA, 1997).

Apesar da variação significativa promovida pelos níveis de nutrientes na solução nutritiva sob a matéria seca foliar das plantas, os valores de $\mathrm{K}$ não se ajustaram a nenhum modelo de regressão que explicasse o fenômeno biológico, obtendo valores oscilando numa amplitude de 47,6 a 52,7 $\mathrm{g} \mathrm{kg}^{-1}$, em função das proporções de nutrientes na solução, sendo representados, portanto pelo valor médio de $49,6 \mathrm{~g} \mathrm{~kg}^{-1}$ de $\mathrm{K}$ (Figura 2C).

Estes valores estão dentro da faixa considerada como ideal para a cultura do pepino que de acordo com Papadopoulos (1994) varia de 35 a $50 \mathrm{~g} \mathrm{~kg}^{-1}$ e para Malavolta, Vitti e Oliveira (1997) é de $50 \mathrm{~g}$ $\mathrm{kg}^{-1}$ e são inferiores a variação de 60 a $100 \mathrm{~g} \mathrm{~kg}^{-1}$ indicados por Vetanovetz (1996) em condições de campo e superiores as concentrações médias de $\mathrm{K}$ nas folhas com teores de $41 \mathrm{~g} \mathrm{~kg}^{-1}$ obtidos por Fernandes, Martinez e Oliveira (2002) em trabalho conduzido com pepino hidropônico.

Apesar da variação significativa promovida pelos níveis de nutrientes na solução sob a matéria seca foliar das plantas, os valores de Ca não se ajustaram a nenhum modelo de regressão, sendo representado pelos teores de cálcio oscilando numa amplitude de 25,1 a 33,9 $\mathrm{g} \mathrm{kg}^{-1} \mathrm{e}$ com valor médio de 29,6 $\mathrm{g} \mathrm{kg}^{-1}$ de cálcio na matéria seca foliar (Figura 2D).

Esses valores foram inferiores a concentração de Ca obtida nas folhas de pepino hidropônico que foi de $62 \mathrm{~g} \mathrm{~kg}^{-1}$ observado por Fernandes, Martinez e Oliveira (2002). Apesar disso, as plantas indicaram que estavam adequadamente nutridas em cálcio, que conforme Jones Júnior, Welf e Mills (1991) consideram ideal a variação de 15 a $40 \mathrm{~g} \mathrm{~kg}^{-1}$.

O pepino absorve e utiliza grande quantidade de nutrientes, mas é muito sensível ao excesso de fertilizantes ou à variação brusca da concentração de fertilizantes na solução do solo, sendo suas raízes bastante susceptíveis a essas variações (PAPADOPOULOS, 1994). Possivelmente, essa oscilação nos teores foliares de $\mathrm{Ca}$ em cada tratamento adotado, seja em função dessa sensibilidade mencionada pelo referido autor.

$\mathrm{O}$ aumento da concentração de nutrientes na solução nutritiva promoveu um aumento linear dos teores de $\mathrm{Mg}$ nas folhas das plantas de pepino (Figura 2E), com aumento de $11,8 \mathrm{~g} \mathrm{~kg}^{-1} \mathrm{em}$ função das proporções de nutrientes na solução nutritiva do menor para o maior teor de $\mathrm{Mg}$ nas folhas das plantas de pepineiro. Tendo os teores do elemento variado de 6,$9 ; 5,6 ; 6,4 ; 7,1$ e 7,7 em função das proporções de nutrientes na solução nutritiva que foram de 12,$5 ; 17 ; 25 ; 50$ e 100\%, respectivamente. Os resultados expressaram que as plantas estavam adequadamente nutridas, uma vez que a faixa admitida adequada de $\mathrm{Mg}$ ao pepineiro situa-se entre 3,5 a 7,0 $\mathrm{g} \mathrm{kg}^{-1}$ (PAPADOPOULOS, 1994) e 5 a $15 \mathrm{~g} \mathrm{~kg}^{-1}$ (VETANOVETZ, 1996).

A aplicação de proporções de nutrientes na solução nutritiva exerceu efeitos significativos sobre os teores foliares de cobre $(\mathrm{Cu})$, ferro $(\mathrm{Fe})$, manganês (Mn) e Zinco ( $\mathrm{Zn}$ ) nas folhas do pepineiro (Tabela 4).

Apesar da significância dos tratamentos em função das proporções de nutrientes na solução, os valores não se ajustaram a nenhum modelo de regressão, com teores de cobre variando de 8,1 a 13,4 $\mathrm{mg} \mathrm{kg}{ }^{-1}$ na matéria seca foliar das plantas (Figura 3A), com valor médio de $9,8 \mathrm{mg} \mathrm{kg}^{-1}$. Mesmo com esse teor médio sendo inferior aos $13,0 \mathrm{mg} \mathrm{kg}^{-1}$ obtidos por Fernandes, Martinez e Oliveira (2002), com plantas de pepino hidropônico, os valores obtidos indicam que as plantas estavam equilibradas nutricionalmente, uma vez que a faixa considerada 
adequada de $\mathrm{Cu}$ em folhas de plantas de pepino situa-se entre 8 a $20 \mathrm{mg} \mathrm{kg}^{-1}$ (PAPADOPOULOS, 1994) e variam de 7 a $10 \mathrm{mg} \mathrm{kg}^{-1}$ (VETANOVETZ, 1996). Considerando-se essas faixas de valores de $\mathrm{Cu}$ encontrados, possivelmente essa variação ocorra porque o cultivo hidropônico proporciona maior absorção de nutrientes pelas plantas quando comparado aos cultivos convencionais, podendose estabelecer níveis críticos superiores para esses produtos (FERNANDES; MARTINEZ; OLIVEIRA, 2002).

Tabela 4. Análises de variância, referentes aos valores de quadrado médio para os teores foliares de cobre $(\mathrm{Cu})$, ferro $(\mathrm{Fe})$, manganês $(\mathrm{Mn})$ e Zinco $(\mathrm{Zn})$ do pepineiro, em função da aplicação de proporções de nutrientes na solução nutritiva.

\begin{tabular}{lccccc}
\hline \multirow{2}{*}{ FV } & & \multicolumn{4}{c}{ Quadrados Médios } \\
\cline { 3 - 6 } & GL & $\mathrm{Cu}$ & $\mathrm{Fe}$ & $\mathrm{Mn}$ & $\mathrm{Zn}$ \\
\hline Bloco & 3 & $13354,583^{\text {ns }}$ & $1231860,600^{\text {ns }}$ & $885722,05088^{*}$ & $334892,850^{\text {ns }}$ \\
SN & 4 & $221835,625^{* *}$ & $13549622,200^{* *}$ & $4432960,925^{* *}$ & $13105773,700^{* *}$ \\
Resíduo & 12 & 9222,2916 & 575822,933 & 307479,758 & 437669,933 \\
\hline CV $(\%)$ & 19 & 9,77 & 8,50 & 6,32 & 6,73 \\
\hline
\end{tabular}

$\mathrm{FV}=$ fonte de variação; $\mathrm{SN}=$ solução nutritiva; $\mathrm{GL}=$ graus de liberdade; $\mathrm{ns}=$ não significativo; * ${ }^{* *}$ respectivamente significativos para $\mathrm{p}<0,05$ e $\mathrm{p}<0,01 ; \mathrm{CV}=$ Coeficiente de variação.

Fonte: Elaboração dos autores.

Figura 3. Teores foliares de cobre (A), manganês (B), ferro (C) e zinco (D) em plantas de pepino, em função de proporções de nutrientes na solução nutritiva.
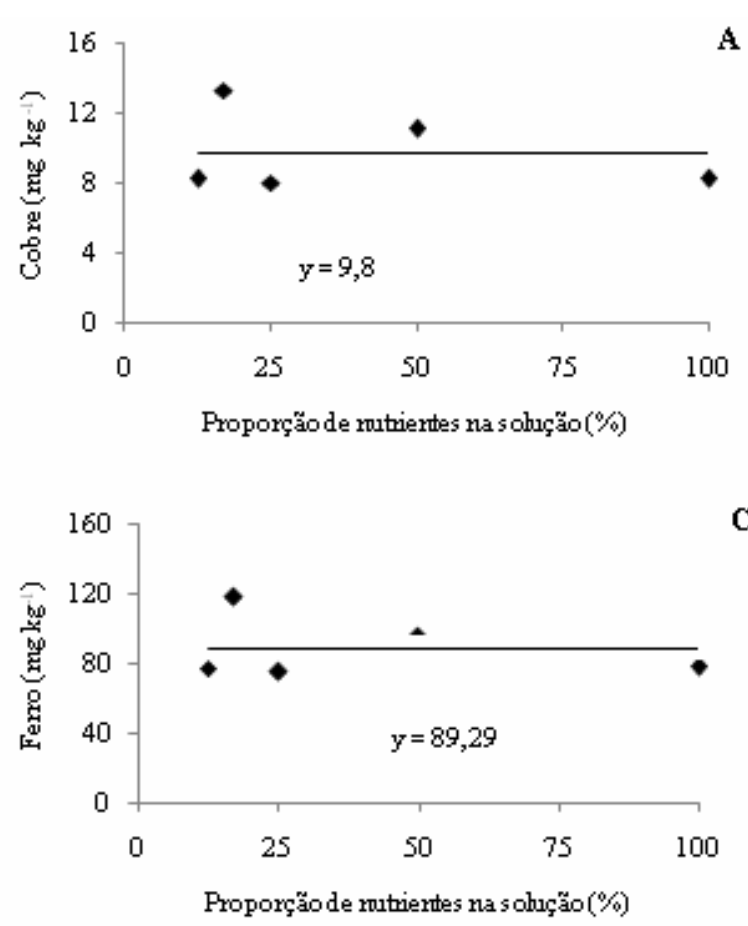

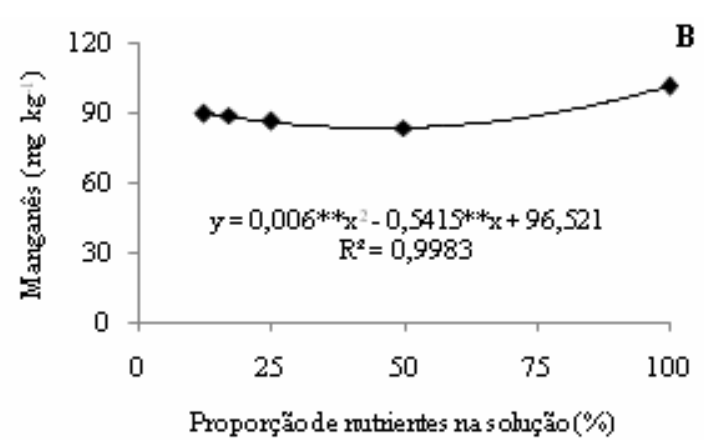

C

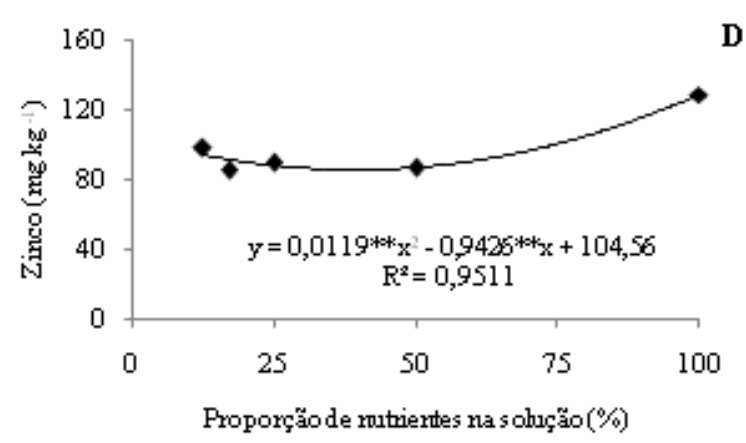

Fonte: Elaboração dos autores. 
Os teores de $\mathrm{Mn}$ nas folhas das plantas variaram com o aumento das proporções de nutrientes na solução de 84,2 a 102,0 mg kg-1 (Figura 3B). As plantas apresentaram teores de manganês dentro da faixa ideal para a cultura, que variam entre 50 a $250 \mathrm{mg} \mathrm{kg}^{-1}$ (PAPADOPOULOS, 1994) e entre 100 a $300 \mathrm{mg} \mathrm{kg}^{-1}$ (VETANOVETZ, 1996). Esse valor é inferior à média de $960 \mathrm{mg} \mathrm{kg}^{-1}$ registrada por Fernandes, Martinez e Oliveira (2002) ao avaliarem plantas de pepino sob hidroponia, os quais registraram altas concentrações de $\mathrm{Mn}$ em plantas de pepino. Sintomas de toxidez de $\mathrm{Mn}$ em pepino aparecem quando as concentrações alcançam 500 e $800 \mathrm{mg} \mathrm{kg}^{-1}$ em folhas jovens e velhas, respectivamente, e significante perda na produção pode ocorrer quando as concentrações atingirem 2.000 e $5.000 \mathrm{mg} \mathrm{kg}^{-1}$ em folhas jovens e velhas, respectivamente (PAPADOPOULOS, 1994). No presente estudo, como as concentrações encontradas estão abaixo desses limites de toxicidade, indicando que as concentrações de Mn utilizadas na solução nutritiva foram adequadas em todos os tratamentos utilizados.

Apesar da significância para os teores de $\mathrm{Fe}$ em função das diferentes proporções de nutrientes encontrados na solução nutritiva, os valores não se ajustaram a nenhum modelo matemático (Figura 3C), apresentando variação de 75,6 a $119,0 \mathrm{mg}$ $\mathrm{kg}^{-1}$, com valor médio de $89,3 \mathrm{mg} \mathrm{kg}^{-1}$. Esses valores foram superiores aos obtidos por Fernandes, Martinez e Oliveira (2002) que obtiveram $43 \mathrm{mg}$ $\mathrm{kg}^{-1}$. Mas, está abaixo da faixa tida como adequada para Vetanovetz (1996) que varia de 100 a 420 $\mathrm{mg} \mathrm{kg}$. A concentração de fertilizantes na água de irrigação, deve ser suficiente para proporcionar a absorção dos nutrientes nas quantidades requeridas pelas plantas, sem causar o acúmulo de fertilizantes no solo, o que poderia resultar em salinização e, consequentemente, na redução da produtividade (BLANCO; FOLEGATTI; NOGUEIRA, 2002).
$\mathrm{O}$ aumento das diferentes proporções de nutrientes na solução nutritiva influenciou a produção de Zn no tecido vegetal das plantas (Figura 3D). O aumento dos níveis de nutrientes na solução nutritiva de 12,5 para até $100 \%$ proporcionou um aumento de 85,5 para até $129,4 \mathrm{mg} \mathrm{kg}^{-1}$, nos tratamentos, o que resultou em aumento dos teores de $\mathrm{Zn}$ acumulado na matéria seca foliar das plantas de pepineiro. Esses valores estão dentro e até acima da faixa tida como ideal para Papadopoulos (1994) que varia de 40 a $100 \mathrm{mg} \mathrm{kg}^{-1}$ e de 90 a $150 \mathrm{mg} \mathrm{kg}^{-1}$ para Vetanovetz (1996).

\section{Conclusões}

O melhor crescimento das plantas em altura e diâmetro caulinar foi obtido com a aplicação de $12,5 \%$ de nutrientes na solução, enquanto que a solução nutritiva diluída a $25 \%$ promoveu maior número de folhas por planta de pepino.

As variáveis nutricionais estudadas foram influenciadas pelas proporções de nutrientes da solução nutritiva; embora em nenhuma proporção a planta mostrou-se com teores nutricionais abaixo do ideal para o crescimento da planta de pepino cultivada em substrato de fibra de coco.

\section{Agradecimentos}

Ao CNPq e a CAPES pelo financiamento da pesquisa e concessão de bolsas.

\section{Referencias}

BLANCO, F. F. Fertirrigação na cultura do pepino. In: BOARETTO, A. E.; VILLAS BÔAS, R. L.; SOUSA, V. F.; PARRA, I. R. V. (Ed.). Fertirrigação: teoria e prática. Piracicaba: [s.n.], 2006. p. 305-330. Disponível em: $<$ http://www.cpamn.embrapa.br/soloaguaclima/ Livroscapituloslivros.php $>$. Acesso em: 19 jan. 2013.

BLANCO, F. F.; FOLEGATTI, M. V.; NOGUEIRA, M. C. S. Fertirrigação com água salina e seus efeitos na produção do pepino enxertado em ambiente protegido. Horticultura Brasileira, Brasília, v. 20, n. 3, p. 442-446, 2002. 
CARDOSO, A. I. I.; WILCKEN, S. R. S. Nematóides assustam produtores de tomate e pepino. Campo \& Negócio, Uberlândia, v.34, n. 1, p. 38-39, 2008.

CARMO FILHO, F.; OLIVEIRA, O. F. Mossoró: um município do semi-árido nordestino, caracterização climática e aspecto florístico. Mossoró: ESAM, 1995. 62 p. (Coleção Mossoroense, série B).

DIAS, N. S.; DUARTE, S. N.; MEDEIROS, J. F. de; TELES FILHO, J. F. Salinidade e manejo da fertirrigação em ambiente protegido. II: Efeitos sobre o rendimento do meloeiro. Irriga, Botucatu, v. 11, n. 3, p. 376-383, 2006.

DIAS, N. S.; LIRA, R. B.; BRITO, R. F.; SOUSA NETO, O. N.; FERREIRA NETO, M.; OLIVEIRA, A. M. Produção de melão rendilhado em sistema hidropônico com rejeito da dessalinização de água em solução nutritiva. Revista Brasileira de Engenharia Agrícola e Ambiental, Campina Grande, v. 14, n. 7, p. 755-761, 2010

FACTOR, T. L.; ARAÚJO, J. A. C.; VILELLAJÚNIOR, V. E. Produção de pimentão em substratos e fertirrigação com efluente de biodigestor. Revista Brasileira de Engenharia Agrícola e Ambiental, Campina Grande, v. 12, n. 2, p. 143-149, 2008.

FERNANDES, A. A.; MARTINEZ, H. E. P.; OLIVEIRA, L. R. Produtividade, qualidade dos frutos e estado nutricional de plantas de pepino, cultivadas em hidroponia, em função das fontes de nutrientes. Horticultura Brasileira, Brasília, v. 20, n. 4, p. 571-575, 2002.

FERREIRA, D. F. Manual do sistema SISVAR para análises estatísticas. Lavras: UFLA, 2000.66 p.
FILGUEIRA, F. A. R. Novo manual de olericultura: agrotecnologia moderna na produção e comercialização de hortaliças. Viçosa, MG: UFV. 2008. 421 p.

FURLANI, P. R.; BOLONHEZI, D.; SILVEIRA, L. C. P.; FAQUIN, V. Nutrição mineral de hortaliças, preparo e manejo de soluções nutritivas. Informe Agropecuário, Belo Horizonte, v. 20, n. 200-201, p. 90-98, 1999.

JONES JÚNIOR, J. B.; WELF, B.; MILLS, H. A. Plant analysis handbook. Athens: Micro-Macro, 1991. 312 p.

MALAVOLTA, E.; VITTI, G. C.; OLIVEIRA, S. A. Avaliação do estado nutricional das plantas: princípios e aplicações. Piracicaba: POTAFOS, 1997. 201 p.

PAPADOPOULOS, A. P. Growing greenhouse seedless cucumbers in soil and in soil less media. Ottawa: Agriculture and Agri-Food Canada Publication, 1994. $126 \mathrm{p}$.

SILVA, G. F.; FONTES, P. C. R.; LIMA, L. P. F.; ARAÚJO, T. O.; SILVA, L. S. Aspectos morfoanatômicos de plantas de pepino (Cucumis sativus L.) sob omissão de nutrientes. Revista Verde, Pombal, v. 6, n. 2, p. 13-20, 2011.

SKREBSKY, E. C. Nutrição mineral e toxidez de cádmio em ginseng brasileiro (Pfaffia glomerata (Spreng.) Pedersen). 2007. Tese (Doutorado em Agronomia) Universidade Federal de Santa Maria, Santa Maria.

VETANOVETZ, R. P. Tissue analysis and interpretation. In: REED, D. W. M. (Ed.). Water, media, and nutrition for greenhouse crops. Batavia: Ball, 1996, p.197-219. 
